\title{
TREE-RING DATING AND RADIOCARBON CALIBRATION IN SOUTH-CENTRAL EUROPE
}

\author{
BERND BECKER \\ Institut für Botanik, Universität Hohenheim, 7000 Stuttgart, Germany
}

ABSTRACT. Radiocarbon variations between 3900 and $2800 \mathrm{BC}$ have been established in La Jolla and Groningen using oak tree rings from a 2350-year floating oak series. Comparison of these variations with the bristlecone pine ${ }^{14} \mathrm{C}$ variations provides precise ages for trec-ring dates of Neolithic settlements of Switzerland and Germany over a period of 1400 years. ${ }^{14} \mathrm{C}$ variations measured in Heidelberg in absolutely dated oakring series from AD 250 to 720 show trends similar to those of long-term growth variation of oaks during the same period of time. The influence of the climatic regime on oak growth of this period is discussed.

\section{Progress in south-central European oak chronology}

Our studies of Holocene tree-ring records for south-central Europe are based on tree-ring analyses of subfossil oak trees that were deposited during the past 8800 years in gravels along the valley floors of the Rhein, Main, and Danube Rivers (Becker, 1979). Some 2100 cross-sections were collected in eastern France, southern Germany, and in the Austrian part of the Danube valley. In addition, oak timbers from numerous prehistoric settlements in southern Germany and in western and eastern Switzerland were cross-dated with the river oak chronologies. At the present stage of investigation, the tree-ring record of the past 8800 years consists of a 2650-year absolute master chronology at the modern end and a number of floating series, each covering 500 to 2300 years (fig 1). M A Geyh, Niedersächsisches Landesamt für Bodenforschung, Hannover, has measured $120{ }^{14} \mathrm{C}$ dates of floating series. The absolute ages of these series were determined by calibration with ${ }^{14} \mathrm{C}$ measurements by $\mathrm{H} \mathrm{E}$ Suess, University of California, San Diego, La Jolla, of known age bristlecone pine wood. The floating series B, C, and D (Hohenheim chronologies Donau 14-Rhein 2-Main 15, Donau 3/10-7/9/12 and Donau 8/15-Main 18) (fig 1) are calibrated by matching La Jolla ${ }^{14} \mathrm{C}$ measurements to bristlecone pine radiocarbon variations using a recently developed computer program (Kruse and others, 1980). For series E (Hohenheim chronology Main 6/13) only a preliminary calibration was given by $\mathrm{H} \mathrm{E}$ Suess. A new set of oak tree rings of this series will be measured in $\mathrm{La}$ Jolla together with samples of one of the oldest part of the bristlecone pine chronology from 6000 to $5400 \mathrm{BC}$, which were prepared by $\mathrm{C} \mathrm{W}$ Ferguson, University of Arizona, Tucson (Suess, pers commun). ${ }^{14} \mathrm{C}$ analyses of series F (Hohenheim chronology Donau 6-Main 4/11) and G (Main 9) dating from the 8th and 9th millennia BC, according to their conventional ${ }^{14} \mathrm{C}$ ages, will be measured by the radiocarbon laboratories in Heidelberg, La Jolla, and Seattle.

\section{Radiocarbon calibration and tree-ring dating: 3900 to 2800 BC}

Suess (1978) published radiocarbon dates of three of our floating oak series, denoted Donau 7/9/12, Main 5, and Donau 3/10. These chronologies have now been linked to a continuous 2350-year record (series $\mathrm{C}$, fig 1 , and Kruse and others, 1980 for details of this linkage.) The ${ }^{14} \mathrm{C}$ 
variations recognized in European oak are synchronous with ${ }^{14} \mathrm{C}$ variations in the bristlecone pine wood. This has been demonstrated with great precision by Suess and Becker (1977) and de Jong, Mook, and Becker (1979) for the period from 3900 to 2800 BC. Figure 2 presents measurements of both laboratories, showing that ${ }^{14} \mathrm{C}$ age variations in European oak wood agree, within experimental errors, with ${ }^{14} \mathrm{C}$ variations in bristlecone pine tree rings of the 4 th millennium Bc. The zero point of our Neolithic-Bronze age oak master chronology, (ie, the oldest tree-ring of the chronology) dates from 4032 BC, according to La Jolla, and from $4035 \mathrm{BC}$, according to Groningen. These results suggest that, so far, the floating European master chronology is the most accurately calibrated record of prehistoric European wood. This is of major importance for the ${ }^{14} \mathrm{C}$ age correction of an increasing number of tree-ring dates from the Neolithic period in Europe. In cooperation with the tree-ring laboratories in Neuenburg (Lambert, Orcel, and Egger), in Zürich (Ruoff), and in Louvain (Munaut), oak timber constructions from more than 20 Neolithic sites in eastern and western Switzerland and southern Germany have been cross-dated with the Hohenheim Neolithic master chronology (Becker and others, 1979). This provides ${ }^{14} \mathrm{C}$ calibrated tree-ring dates of the Pfyn, Cortaillod, Horgen, and Lüscherz cultures over a continuous 1400-year tree-ring scale from 3800 to 2400 BC. In this way, by cross-dating with the Hohenheim Neolithic master chronology, two Swiss oak chronologies spanning 407 and 834 years have been established, dating from 4035 to $3629 \mathrm{BC}$ and 3448 to $2615 \mathrm{BC}$, respectively (fig 3).

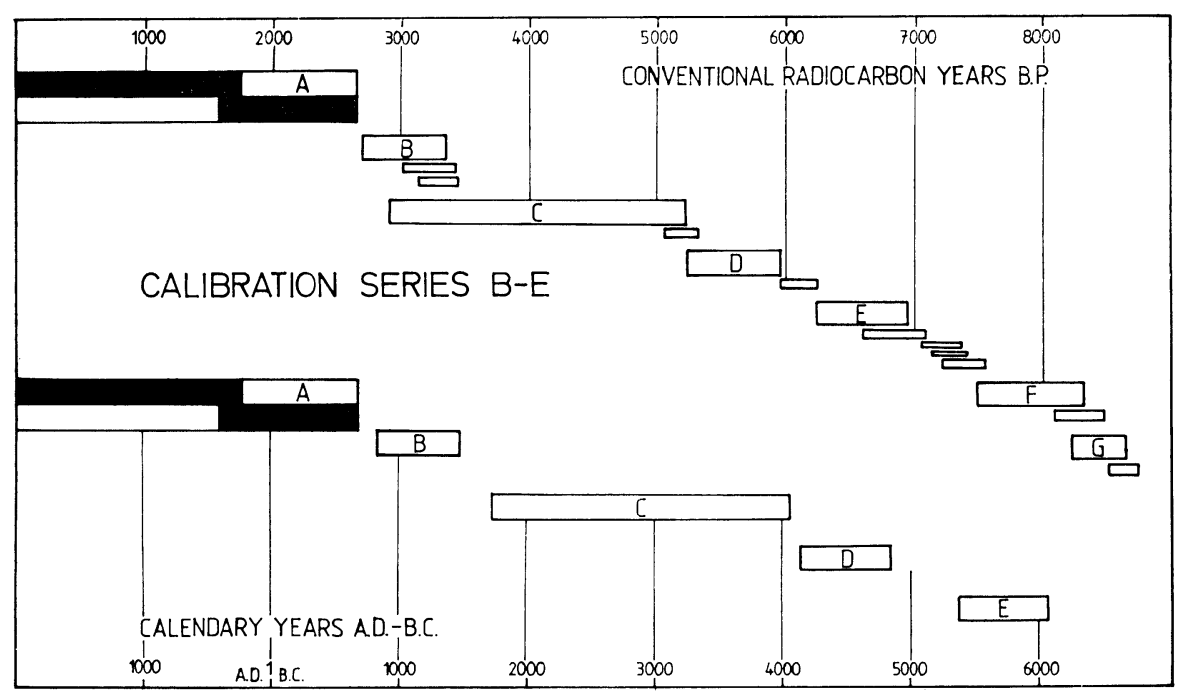

Fig 1. Present stage of the Holocene oak tree-ring chronology in South Central Europe. Upper part: floating chronologies plotted according to their conventional radiocarbon ages ВP. Lower part: the same series plotted according to their calibrated radiocarbon ages Bc. The floating chronologies are developed in cooperation with $\mathbf{A}$ Delorme, Univ Göttingen, Germany. 
Radiocarbon calibration and tree-growth variation, $\mathrm{AD} 200$ to 800

Michael Bruns, Heidelberg, recently performed precise ${ }^{14} \mathrm{C}$ analyses on oak wood from the absolutely-dated Hohenheim early Medieval treering chronology, Donau 5. The trees used were deposited along the upper Danube valley between Ulm and Ingolstadt. The amplitudes of ${ }^{14} \mathrm{C}$ variations correspond to those observed by de Jong for 4th millennium BC wood (Bruns, de Jong, and Becker, 1980). Moreover, Bruns found a correlation between radiocarbon and growth trends computed by raw ring-width data of our master chronology. A re-investigation of the growth variations by use of age-trend corrected tree-ring data has confirmed this correlation. For the age-trend corrections of a total number of 120 crossdated oaks grown between AD 200 and 800, we used a method first applied by Hollstein (1977). The annual tree-ring variations of each tree were

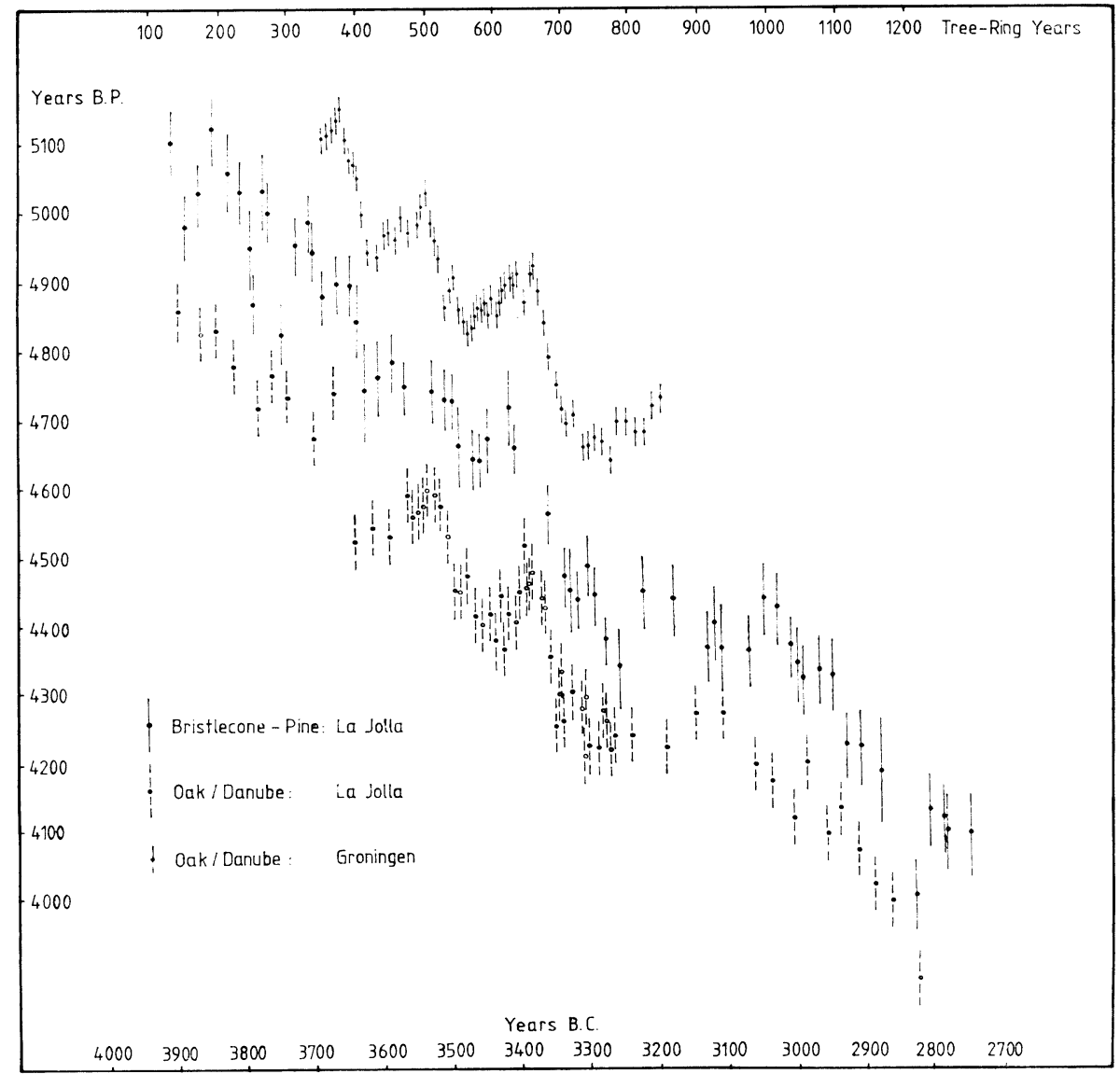

Fig 2. Radiocarbon calibration of the Neolithic oak master-chronology 3900 to 2700 BC. ${ }^{14} \mathrm{C}$ measurements of oak are plotted against bristlecone pine radiocarbon variation of the La Jolla laboratory. For better comparison, the variations for oak are shifted on the conventional ${ }^{14} \mathrm{C}$ time scale by 200 years in the upper and in the lower data set. 
calculated as logarithms of the ratio of the year-to-year ring widths, and then the transferred data were matched to a master chronology. By adding the mean annual ratios, a growth trend curve was then calculated. This curve is independent of variations that can be caused by incorporating tree-ring data of both rapidly and slowly growing trees. This growth curve is plotted in figure 4 against its ${ }^{14} \mathrm{C}$ values. The chronology between AD 250 and 650 is represented at each point by 10 to 70 cross-matched trees. Therefore, during this period, growth ratios are well-established. Parallel trends in tree growth and ${ }^{14} \mathrm{C}$ can be recognized for the periods of decreasing values $\mathrm{AD} 280$ to 400 and 430 to 550 , as well as for those of increasing values during AD 400 to 440,550 to 620 , and 680 to 720 .

\section{Patterns of the early Medieval oak growth variations}

Long-term growth variations of oaks grown along the Danube valley from $\mathrm{AD} 200$ to 800 are caused by two different factors. This is demonstrated in figure 5 by plots of ring width (10-year means) versus year for seven long-living oaks of this series. One factor is the variation of the age-trends depending on the period when each tree started growing. It can be seen that age trends, $i e$, high growth rates during the juvenile phase, followed by a general decrease of growth rates with increasing tree age, are pronounced regularly during phases for which the general trend is high. During phases of low tree growth, however, age trends are remarkably reduced or even absent. This can be seen, for example, in figure 5 for oaks which started growing between $\mathrm{AD} 300$ and 400 . The second factor is that long-lived trees sometimes show an increase of growth even at older age. This increase is an exception to the normal age trend, which is a negative slope in older trees. Most remarkably, this exception is only observed during periods of increasing ${ }^{14} \mathrm{C}$.

The reason that long-term tree growth variations in the age-trend uncorrected as well as in the age-trend corrected master chronology of that

\begin{tabular}{|lll}
\hline Zero Point 4035 B.C. Neolithic master chronology Stuttgart-Hohenheim $\quad$ Continues to 1722 B.C. \\
\hline
\end{tabular}
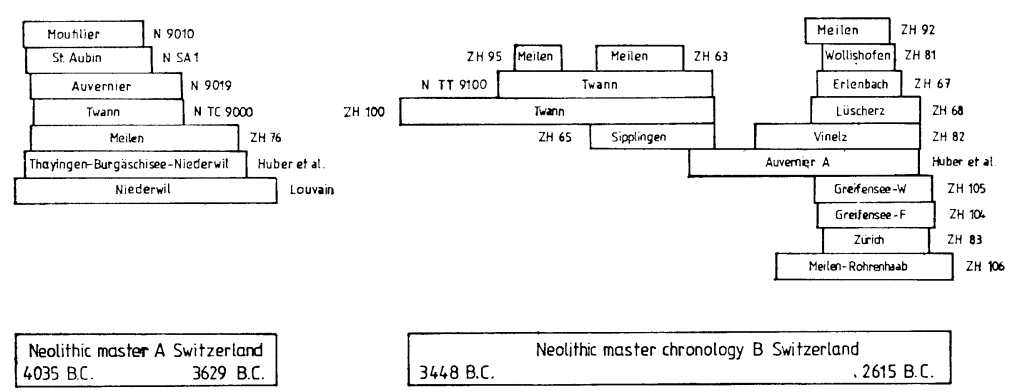

\begin{tabular}{llll}
\hline 4000 B.C. & 3500 B.C. & 3000 B.C. & 2500 B.C.
\end{tabular}

Fig 3. Present stage of the Ncolithic Swiss oak chronologies in their cross-dated position to the Hohenheim Neolithic master-chronology. 


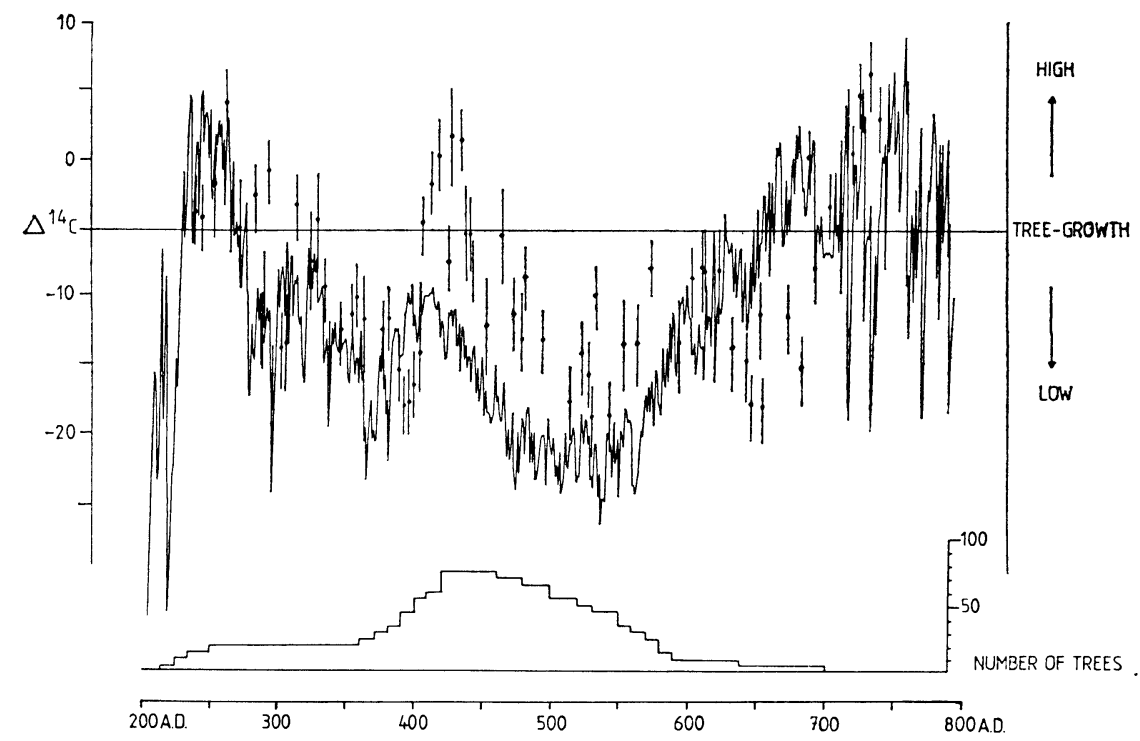

Fig 4. Long-term growth-trend variations, derived from 120 cross-dated oaks and their ${ }^{14} \mathrm{C}$ variations, AD 250 to 720 .

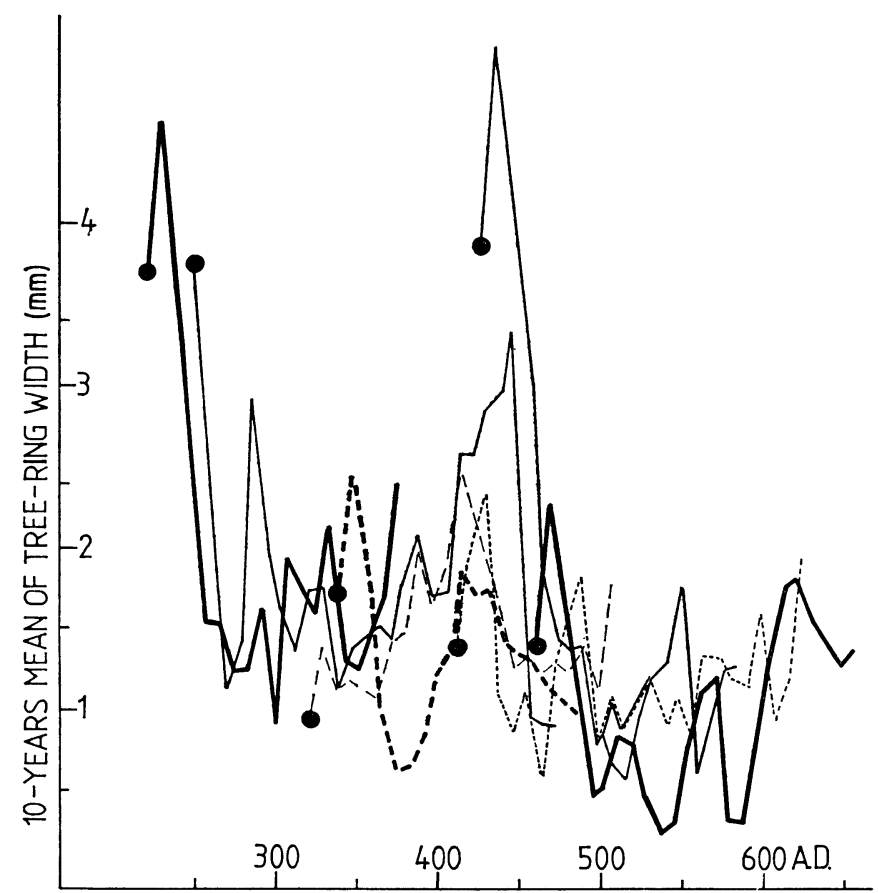

Fig 5. Age trends of seven longliving Early Medieval oaks, plotted by 10-year means of ring width. 
period can be observed is that both age-trend and growth variations in long-lived trees change in the same direction during the entire period. In standardized tree-ring chronologies for which age-trends are removed by polynomial regression functions, a method used for dendroclimatic studies, tree growth variations of the type discussed here should not be expected.

From paleoecologic, geologic, and paleopedologic studies of the fluvial environment of our valley oak sites during the past 8800 years, we know that changes in oak growth rates from Early to Late Holocene did occur (Becker and Schirmer, 1978; Becker, 1978a). It can also be deduced from these studies that river oaks, which had been eroded and deposited by the pronounced early Medieval fluvial activities, grew under favorable ecologic conditions on deep-reaching flood-loam soils with well-balanced water supply. This agrees with the observation that most rapidly grown and large subfossil oaks are found in gravel deposits of just that period.

We can, therefore, essentially exclude changes of site conditions or different patterns of alluvial sites at that time as a factor causing the observed growth variations. High-standing and long-lasting floods that can cause tree-ring growth depressions by damaging root systems of oaks, seem to be recorded surprisingly infrequently in Holocene oak patterns. The significant agreement between tree-ring curves of river oaks and oak chronologies from archaeologic sites outside the valleys could not be explained in another manner. An example of the excellent cross-correlation between river and hilly site oak series from early Medieval times is given
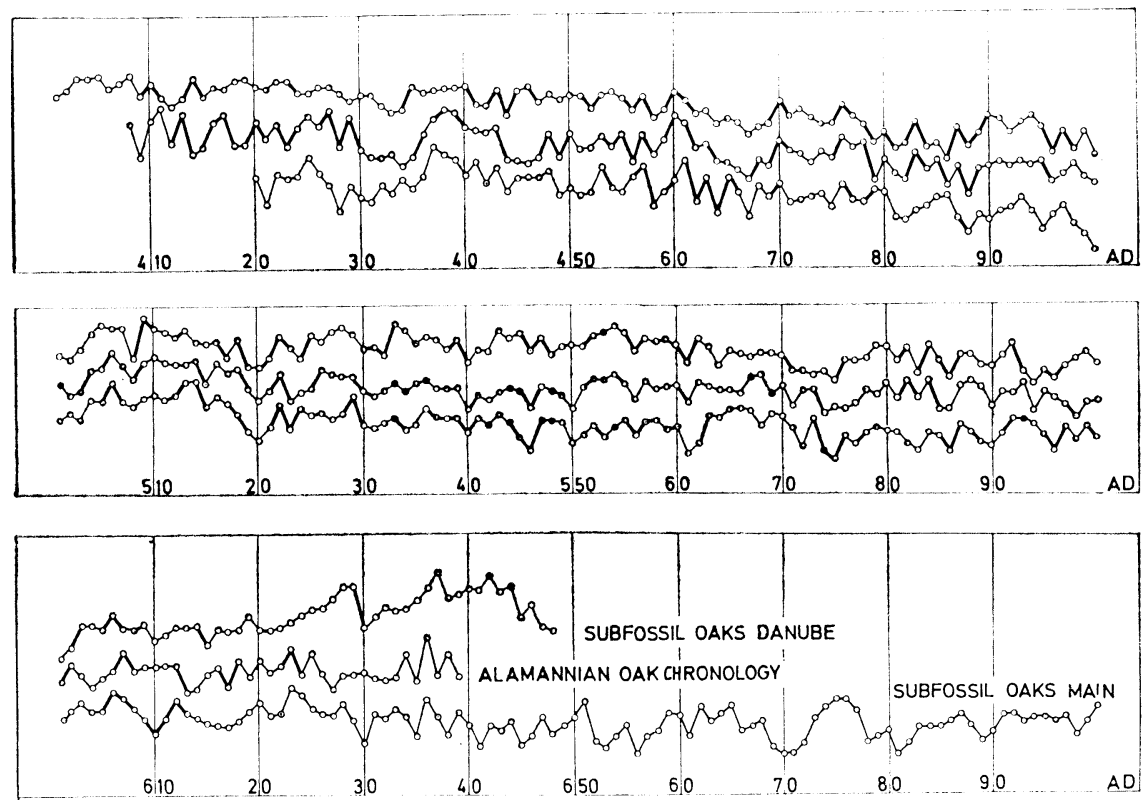

Fig 6. Comparison of tree-ring master-chronologies from the valleys of the Danube and Main with a chronology of hilly site oaks derived from coffins of cemeteries of the Alamannian period (Hüfingen and Oberflacht, South Germany). 
in figure 6. However, if flood periods can be observed in oak growth records, then tree growth depressions appear to last no longer than 10 to 15 years. An example for subfossil oaks showing this type of short-term depression is given by Suess (1979).

In conclusion, the most probable factor controlling the growth pattern of oaks along the Danube Valley between AD 200 and 800 must have been the climatic regime. The way in which oaks from wet, as well as dry sites respond to climate today has been studied on living oaks and beeches grown at two sites in the vicinity of Stuttgart. As shown in figure 7 , warm temperatures and low precipitation during the growth period are correlated with slow oak growth rates. It is interesting to note that, in the long-term trend, a correlation with precipitation is present, especially in the oak patterns during the period 1930 to 1970 . We do not know whether the oaks from AD 200 to 800 responded to a similar climatic pattern. At the present stage of investigation the possibility cannot be excluded that the described correlation between tree growth and ${ }^{14} \mathrm{C}$ variation is coincidental. However, we will attempt, in the next phase of this study, to investigate long-term growth patterns of Neolithic as well as of Mediaeval oaks for which the ${ }^{14} \mathrm{C}$ variations are precisely established. If this type of correlation can be found again, the possibility that medium-term variations of atmospheric ${ }^{14} \mathrm{C}$ production are correlated with climatic variations as recorded in European tree-ring patterns will have to be considered.

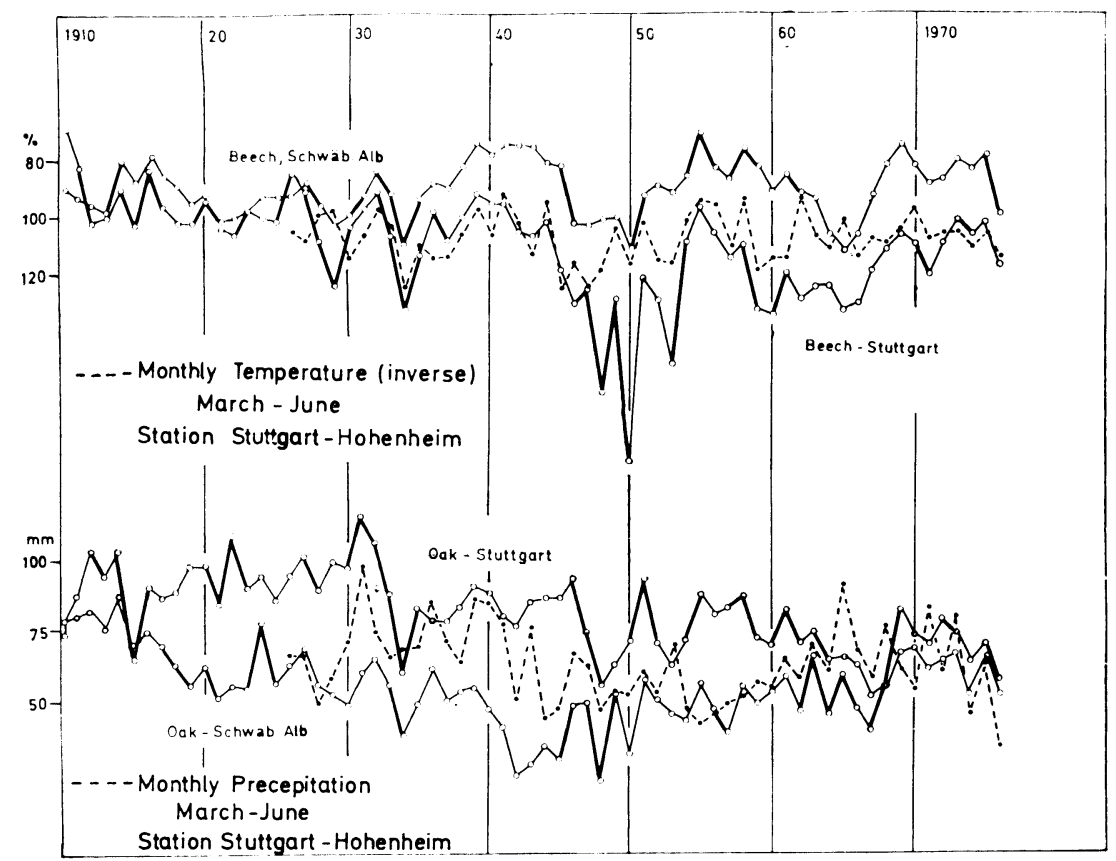

Fig 7. Correlation between tree-ring variation of oak and beech (sites near Stuttgart and from Schwäbische Alb Mountains) and monthly precipitation temperature of the period March to June recorded at Hohenheim from 1926 to 1976. 


\section{REFERENCFS}

Becker, Bernd, 1978a, Beiträge zur postglazialen Landschaftsentwicklung des Donautales, in Nagl, H, ed, Beiträge zur Quartär und Landschaftsforschung: Vienna, F Hirt, p 23-35.

1978b, Dendroecological zones of central European forest communities, in Fletcher, J, ed, Dendrochronology in Europe: BAR interntl ser 51, p 101-114.

1979, Holocene tree-ring series from southern central Europe for archaeologic dating, radiocarbon calibration, and stable isotope analysis, in Berger, Rainer and Suess, H E, eds, Radiocarbon dating, Internatl radiocarbon conf, 9th, Proc: Berkeley/Los Angeles, Univ California Press, p 554-565.

Becker, Bernd, Orcel, Chr, Egger, H, and Ruoff, U, 1979, Drei Beiträge zur Chronologie des Neolithikums in der Schweiz: Zeitschr f Schweizer Archäol u Kunstgesch, v 36 H 2, p 91-96.

Becker, Bernd and Schirmer, Wolfgang, 1977, Palaeoecological study on the Holocene valley development of the River Main, S-Germany: Boreas, v 6, p 303-321.

Hollstein, Ernst, 1977, Eichenchronologie Westdeutschlands und der Schweiz aus römischer und vorrömischer Zeit, in Frenzel, B, ed, Dendrochronologie und postglaziale Klimaschwankungen: Wiesbaden, F Steiner, Erdwiss Forschung, v 13, p 16-24.

de Jong, A F M, Mook, W G, and Becker, Bernd, 1979, Confirmation of the Suess wiggles 3200-3700 вC: Nature, v 280, p 48-49.

Kruse, H H, Linick, T W, Suess, H E, and Becker, Bernd, 1980, Computer-matched radiocarbon dates of floating tree-ring series, in Stuiver, Minze and Kra, Rence, eds, Internatl radiocarbon conf, 10th, Proc: Radiocarbon, v 22, no. 2, p 260-266.

Suess, H E, 1978, La Jolla measurements of radiocarbon in tree-ring dated wood: Radiocarbon, v 20, p $1-18$.

1979 Ist die Sonnenfleckenaktivität für Klimaschwankungen verantwort lich?: Umschau, v 10, p 312-317. 